University of Nebraska - Lincoln

DigitalCommons@University of Nebraska - Lincoln

$11-25-2002$

\title{
Heterojunction diode fabrication from polyaniline and a ferroelectric polymer
}

\author{
$\mathrm{B}$ Xu \\ University of Nebraska-Lincoln \\ Y. Ovchenkov \\ University of Nebraska-Lincoln \\ Mengjun Bai \\ University of Nebraska-Lincoln, baime@missouri.edu
}

A. N. Caruso

University of Nebraska-Lincoln, carusoan@umkc.edu

\author{
A.V. Sorokin \\ University of Nebraska-Lincoln
}

See next page for additional authors

Follow this and additional works at: https://digitalcommons.unl.edu/physicsdowben

Part of the Physics Commons

Xu, B; Ovchenkov, Y.; Bai, Mengjun; Caruso, A. N.; Sorokin, A.V.; Ducharme, Stephen; Doudin, Bermard; and Dowben, Peter A., "Heterojunction diode fabrication from polyaniline and a ferroelectric polymer" (2002). Peter Dowben Publications. 16.

https://digitalcommons.unl.edu/physicsdowben/16

This Article is brought to you for free and open access by the Research Papers in Physics and Astronomy at DigitalCommons@University of Nebraska - Lincoln. It has been accepted for inclusion in Peter Dowben Publications by an authorized administrator of DigitalCommons@University of Nebraska - Lincoln. 


\section{Authors}

B Xu, Y. Ovchenkov, Mengjun Bai, A. N. Caruso, A.V. Sorokin, Stephen Ducharme, Bermard Doudin, and Peter A. Dowben 


\title{
Heterojunction diode fabrication from polyaniline and a ferroelectric polymer
}

\author{
B. Xu, Y. Ovchenkov, M. Bai, A. N. Caruso, A. V. Sorokin, Stephen Ducharme, \\ B. Doudin, and P. A. Dowben ${ }^{\mathrm{a}}$ \\ Department of Physics \& Astronomy, Center for Material Research and Analysis, Behlen Laboratory \\ of Physics, University of Nebraska-Lincoln, Lincoln, Nebraska 68588-0111
}

(Received 30 July 2002; accepted 2 October 2002)

\begin{abstract}
We have fabricated a $p-n$ heterojunction diode by vapor depositing a thin film of polyaniline on top of the crystalline copolymer: poly(vinylidene fluoride with trifluoroethylene). The formation of a diode is expected from the band offsets of the two polymers near the Fermi level. The interface between the two components was investigated, and an abrupt interface was found that is very different from the inorganic analog. (C) 2002 American Institute of Physics.
\end{abstract}

[DOI: $10.1063 / 1.1524695]$

Conjugated polymers have attracted enormous attention since the discovery of an appreciable conductance in these materials. ${ }^{1-5}$ Conjugated polymers are appealing candidates for low-cost, flexible electronics applications, and as possible replacements for conventional metals and inorganic semiconductors, and there has been considerable progress in the fabrication of devices using different semiconductor polymers. ${ }^{6-9}$

A mechanism for the control of the dipole layer at a device interface is to employ ferroelectrics-materials with a strong intrinsic (reversible) dipole-as one element. Recently, a diode was fabricated using a ferroelectric perovskite and a magnetic perovskite junction, ${ }^{10}$ but the complexity of perovskite interfaces ${ }^{11-13}$ diminishes the insights possible from such a device. Polymers actually offer a route for more precise control of the interface composition and relating the band edge offsets to the diode performance, when involving a ferroelectric material. Recently, high quality films of ferroelectric copolymer of vinylidene fluoride and trifluoroethylene, PVDF-TrFE, have been fabricated using the LangmuirBlodgett (LB) monolayer (ML) transfer technique. ${ }^{14-16}$ The molecular units (or monomers) with net dipole moments, which point from the electronegative fluorine to the electropositive hydrogen, form chains crystallizing in parallel rows. There is no apparent critical thickness in these LB films, and ferroelectricity is preserved in films as thin as one nanometer. ${ }^{15-17}$

In this letter, we report measurement of the band offsets, relative to the Fermi level, of PVDF-TrFE, polyaniline, and doped polyaniline films, with vapor exposure to iodine ${ }^{18}$ in stages as the film was grown. These $p$-type ${ }^{18}$ and $n$-type ${ }^{19}$ polymers are combined to form the appropriate heterojunction $p-n$ diodes. The band positions, relative to the Fermi level, of PVDF-TrFE films and pure/doped polyaniline covered PVDF-TrFE films, with each polymer about 5 ML thick, were determined though inverse photoemission spectroscopy (IPES) and photoemission spectroscopy (PES), undertaken in the same UHV chamber, as described elsewhere. ${ }^{18,19}$ For the

\footnotetext{
a) Author to whom correspondence should be addressed; electronic mail: pdowben@unl.edu
}

perpendicular transport measurements, mesa structures were fabricated by growing nominally $30 \mathrm{ML}$ (about $1.7 \mathrm{~nm} / \mathrm{ML}$ ) of crystalline PVDF-TrFE copolymer films on aluminum, again using the LB ML deposition from a water subphase. ${ }^{14-16}$ These were then used as substrates for the vapor deposited polyaniline thin films ${ }^{18,20}$ with polyaniline polymer films about 80 molecules $(200 \AA)$ thick.

The binding energies of the highest occupied molecular orbital (HOMO) and the lowest unoccupied molecular orbital (LUMO) relative to the Fermi level, as well as the effective gap between the conduction band edge and valence band edge, for LB PVDF-TrFE crystalline films and vapor deposited polyaniline films are evident from the combined IPES and PES studies, as seen in Fig. 1. The band edges are determined from fitting experimental spectra with Gaussian functions with the cutoffs placed at $1 / e$ of the intensity at the band edge. The band gaps and binding energies of the HOMO and LUMO bands are strongly temperature depen-

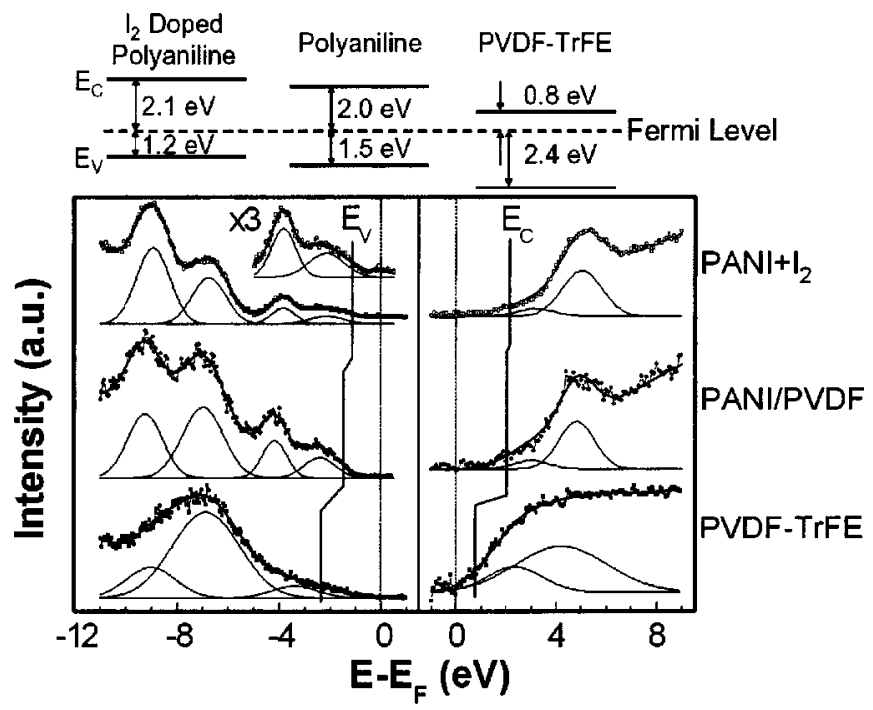

FIG. 1. Photoemission and inverse photoemission spectra of clean (PVDFTrFE) and polyaniline covered (PANI) PVDF-TrFE films as well as iodine doped polyaniline $\left(\mathrm{PANI}+\mathrm{I}_{2}\right.$ ). The spectra are fitted using Gaussian functions, and the relative shifts in the edges of valence band and conduction band are shown using vertical bars. The corresponding energy levels of these components are schematically shown at the top of the figure. 


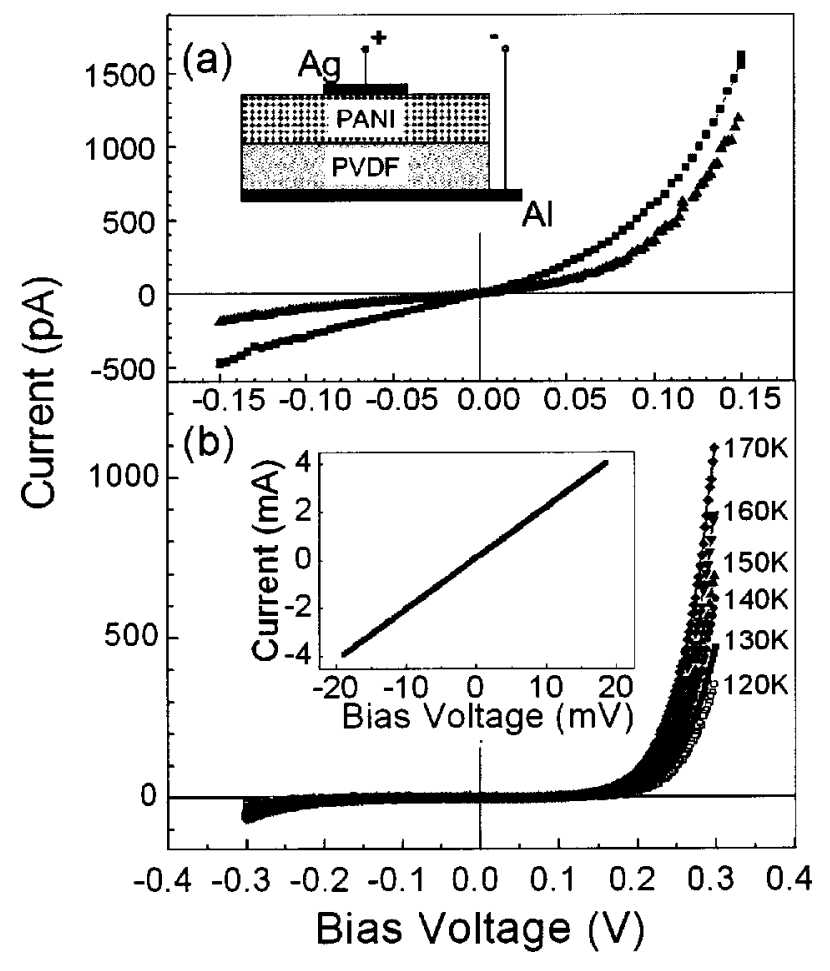

FIG. 2. $I-V$ characteristics of diodes fabricated from PVDF-TrFE (30 ML thick) and polyaniline [200 $\AA$ ( $80 \mathrm{ML})$ thick]. Two different kinds of polyaniline, pristine as well as iodine doped, were used in the diode fabrication. The corresponding room temperature $I-V$ curves are shown in (a), with (-口-) and (- $\left.\boldsymbol{\Delta}_{-}\right)$for pristine and iodine doped polyaniline, respectively. Temperature dependence of the $I-V$ curves from the diode made by PVDF-TrFE and iodine doped polyaniline is shown in (b). The schematic structure of the diode is indicated as an inset to (a). The contact (nonrectifying) contributions are shown as an inset in (b).

dent for PVDF-TrFE. ${ }^{19,21}$ Nonetheless, as previously noted,${ }^{18-20}$ from the position of the HOMO and LUMO states and the position of the valence and conduction band edges, as determined by PES and IPES at room temperature (Fig. 1), the ferroelectric PVDE-TrFE can be considered an $n$-type semiconductor, while vapor deposited polyaniline is of $p$-type character. Doping studies of polyaniline have demonstrated that the subtraction of electrons from the polyaniline system, by doping with iodine, leads to a decrease in binding energy in all the bands, ${ }^{18}$ enhancing the $p$-type character of this polymeric semiconductor, as seen in Fig. 1. Because of the band offsets, schematically illustrated in Fig. 1, it should be possible to fabricate a heterojunction diode with a PVDF-TrFE and polyaniline (both doped and undoped) bilayer.

Heterojunction $p-n$ diode structures from PVDF-TrFE and polyaniline, schematically shown as an inset in Fig. 2(a), indeed result in devices with excellent diode characteristics. Rectification is evident in the $I-V$ curves of two diodes, both from a PVDF-TrFE/polyaniline bilayer and PVDF-TrFE with iodine doped with polyaniline, as shown in Fig. 2(a). With iodine doping, the polyaniline becomes more $p$-type, and the density of minority charge carrier decreases. As the saturation (leakage) current is generally determined by the density of minority charge carriers, for the same bias voltage, the resulting current should decrease for the $p-n$ junction fabricated from iodine-doped polyaniline, as is indeed observed in the experiment. atoms can. By way of comparison, there is little emission
served in the experiment.
Downloaded 05 Sep 2006 to 129.93.16.206. Redistribution subject to AlP license or copyright, see http://apl.aip.org/apl/copyright.jsp

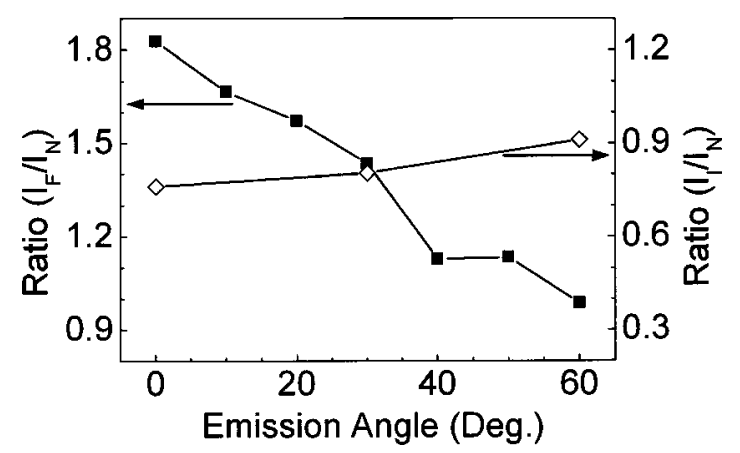

FIG. 3. The ARXPS intensity ratios, representative of the two polymers: $\mathrm{F} 1 s$ from PVDF-TrFE, and $\mathrm{N} 1 s$ from polyaniline. The emission angle dependence is a characteristic signature that the 20 -A -thick polyaniline film resides on top of $30-\AA$-thick PVDF-TrFE film. Also shown is the emission angle dependence of the iodine $3 d$ core level relative to the polyaniline $\mathrm{N} 1 s$ core level intensities. The absence of emission angle dependence indicates that the iodine is well mixed throughout the sampling region of the polyaniline layer.

This rectification is not a consequence of ferroelectric switching, as the coercive voltage for a ferroelectric film of a 30 ML crystalline PVDF-TrFE is much larger than the applied fields herein, typically several volts or more as seen from the pyroelectric hysteresis loop. ${ }^{17,22,23}$ The role of the contacts was investigated, and several contact/ground plane materials were tested. The contacts alone act as a resistor, as seen in the inset to Fig. 2(b).

The $p-n$ heterojunction fabricated from PVDF-TrFE and iodine-doped polyaniline exhibits the typical temperature characteristics of a $p-n$ junction diode. In Fig. 2(b), temperature dependent $I-V$ curves, from 120 to $170 \mathrm{~K}$, are shown for the iodine doped polyaniline/PVDF-TrFE diode. When the temperature increases, the density of charge carriers should increase dramatically, as should the saturation current. This behavior, as seen in Fig. 2(b), could well be enhanced by the decrease in the effective HOMO-LUMO gap in PVDF-TrFE, ${ }^{19}$ with increasing temperature. (Even more significant gap and metallicity changes have been observed in the manganese perovskites. ${ }^{12,24}$ ) The effects due to the changes in band gap have not, as yet, been specifically delineated.

The interfaces between polymers and metals usually are not abrupt ${ }^{25-27}$ because the metals diffuse into the polymer at the interface. The interface between polyaniline and PVDF-TrFE was studied using angle-resolved $\mathrm{x}$-ray photoemission spectroscopy (ARXPS), as shown in Fig. 3. The ratio of $\mathrm{F} 1 s$ to $\mathrm{N} 1 s$ core level photoemission intensities, selected as representative of PVDF-TrFE (F $1 s)$ and polyaniline ( $\mathrm{N} 1 s)$ shows that the F $1 s$ core level intensity decreases with respect to the $\mathrm{N} 1 s$ core level intensity as a function of increasing electron emission angle. As the electron mean free path of the photoelectrons is quite small (of order $1 \mathrm{~nm}$ ), with increasing emission angle, the polyaniline is preferentially sampled with respect to the PVDF-TrFE. This dependence of the core level XPS intensities suggests the interface between these two polymers is quite abrupt, whereas metal deposition (on the polymer), ${ }^{27}$ or the perovskite interface ${ }^{11-13}$ is not. This is the result we expect: Large molecules cannot readily interdiffuse, while the individual 
angle dependence for iodine core level intensity relative to the polyaniline $\mathrm{N} 1 s$ core level intensity as a function of emission angle. This indicates that the iodine is relatively isotropically distributed throughout the polyaniline film.

In conclusion, the structural and electronic properties of the interface between polyaniline and PVDF-TrFE were investigated by combined PES and IPES and are consistent with the observed diode properties.

This work was supported by the Office of Naval Research, the Nebraska Research Initiative and the Petroleum Research Fund administrated by the ACS.

${ }^{1}$ C. K. Chiang, C. R. Fincher, Y. W. Park, A. J. Heeger, H. Shirakawa, E. J. Louis, and A. G. MacDiarmid, Phys. Rev. Lett. 39, 1098 (1977).

${ }^{2}$ H. Shirakawa, E. J. Louis, A. G. MacDiarmid, C. K. Chiang, and A. J. Heeger, Chem. Commun. (Cambridge) 16, 578 (1977).

${ }^{3}$ A. J. Heeger, Rev. Mod. Phys. 73, 681 (2001).

${ }^{4}$ A. G. MacDiarmid, Rev. Mod. Phys. 73, 701 (2001).

${ }^{5}$ H. Shirakawa, Rev. Mod. Phys. 73, 713 (2001).

${ }^{6}$ R. H. Friend, R. W. Gymer, A. B. Holmes, J. H. Burroughes, R. N. Marks, C. Taliani, D. D. C. Bradley, D. A. Dos Santos, J. L. Brédas, M. Lögdlund, and W. R. Salaneck, Nature (London) 397, 121 (1999).

${ }^{7}$ H. Sirringhaus, N. Tessler, and R. H. Friend, Science 280, 1741 (1998).

${ }^{8}$ G. Yu, J. Wang, J. McElvain, and A. J. Heeger, Adv. Mater. 10, 1431 (1998).

${ }^{9}$ N. S. Sariciftci, Curr. Opin. Solid State Mater. Sci. 4, 373 (1999).

${ }^{10}$ H. Tanaka, J. Zhang, and T. Kawai, Ferroelectr. 88, 027204 (2002).

${ }^{11}$ J. Choi, C. Waldfried, S.-H. Liou, and P. A. Dowben, J. Vac. Sci. Technol. A 16, 2950 (1998); J. Choi, J. Zhang, S.-H. Liou, P. A. Dowben, and E. W. Plummer, Phys. Rev. B 59, 13453 (1999).

${ }^{12}$ H. Dulli, E. W. Plummer, P. A. Dowben, J. Choi, and S.-H. Liou, Appl. Phys. Lett. 77, 570 (2000).
${ }^{13}$ C. N. Borca, B. Xu, T. Komesu, H. Jeong, M. T. Liu, S.-H. Liou, and P. A. Dowben, Surf. Sci. Lett. 512, L346 (2002).

${ }^{14}$ S. Palto, L. Blinov, A. Bune, E. Dubovik, V. M. Fridkin, N. Petuknova, K. Verkhovskaya, and S. Yudin, Ferroelectr. Lett. Sect. 19, 65 (1995).

${ }^{15}$ L. M. Blinov, V. M. Fridkin, S. P. Palto, A. V. Bune, P. A. Dowben, and S. Ducharme, Usp. Fiz. Nauk 170, 247 (2000); Phys. Usp. 43, 243 (2000).

${ }^{16}$ S. Ducharme, S. P. Palto, V. M. Fridkin, and L. M. Blinov, in Handbook of Surfaces and Interfaces of Materials, Vol. 3: Ferroelectric and Dielectric Thin Films, edited by H. S. Nalwa (Academic, Texas, 2001).

${ }^{17}$ A. V. Bune, V. M. Fridkin, S. Ducharme, L. M. Blinov, S. P. Palto, A. V. Sorokin, S. G. Yudin, and A. Zlatkin, Nature (London) 391, 874 (1998).

${ }^{18}$ B. Xu, J. Choi, A. N. Caruso, and P. A. Dowben, Appl. Phys. Lett. 80, 4342 (2002).

${ }^{19}$ J. Choi, P. A. Dowben, S. Pebley, A. Bune, S. Ducharme, V. M. Fridkin, S. P. Palto, and N. Petukhova, Phys. Rev. Lett. 80, 1328 (1998).

${ }^{20}$ J. Choi, M. Chipara, B. Xu, C. S. Yang, B. Doudin, and P. A. Dowben, Chem. Phys. Lett. 343, 193 (2001).

${ }^{21}$ C. N. Borca, S. Adenwalla, J. Choi, P. T. Sprunger, S. Ducharme, L. Robertson, S. P. Palto, J. Liu, M. Poulsen, V. M. Fridkin, H. You, and P. A. Dowben, Phys. Rev. Lett. 83, 4562 (1999).

${ }^{22}$ A. V. Bune, S. Ducharme, V. M. Fridkin, L. M. Blinov, S. P. Palto, N. Petuknova, and S. Yudin, Appl. Phys. Lett. 67, 3975 (1995).

${ }^{23}$ S. Ducharme, S. P. Palto, L. M. Blinov, and V. M. Fridkin, AIP Conf. Proc. 535, 354 (2000).

${ }^{24}$ C. N. Borca, B. Xu, T. Komesu, H. Jeong, M. T. Liu, S.-H. Liou, S. Stadler, Y. Idzerda, and P. A. Dowben, Europhys. Lett. 56, 722 (2001).

${ }^{25}$ M. Lögdlund, R. Lazzaroni, S. Stafström, W. R. Salaneck, and J. L. Brédas, Phys. Rev. Lett. 63, 1841 (1989).

${ }^{26}$ M. Lögdlund, P. Dannetun, S. Stafström, W. R. Salaneck, M. G. Ramsey, C. W. Spangler, C. Fredriksson, and J. L. Brédas, Phys. Rev. Lett. 70, 970 (1993).

${ }^{27}$ B. Xu, C. N. Borca, S. Ducharme, A. V. Sorokin, P. A. Dowben, V. M. Fridkin, S. P. Palto, N. N. Petukhova, and S. G. Yudin, J. Chem. Phys. 114, 1866 (2001). 